\title{
A rare cause of iron deficiency anemia in a child: Lithobezoar
}

\section{Çocuklarda demir eksikliği anemisinin nadir bir sebebi: Litobezoar}

\author{
Yasemin Altuner Torun'1, Edip Torun², Ayşe Betül Ergül ${ }^{3}$, Musa Karakükçü4, \\ Türkan Patıroğlu ${ }^{4}$ \\ ${ }^{1}$ Department of Pediatrics, Division of Pediatric Hematology, Kayseri Education and Research Hospital, Kayseri, Turkey \\ ${ }^{2}$ Department of Gastroenterology, Faculty of Medicine, Erciyes University, Kayseri, Turkey \\ ${ }^{3}$ Department of Pediatrics, Division of Pediatrics, Kayseri Education and Research Hospital, Kayseri, Turkey \\ ${ }^{4}$ Department of Pediatric Hematology, Faculty of Medicine, Erciyes University Kayseri, Turkey
}

Bezoars are the accumulation of undigested foreign bodies or food material in the gastrointestinal tract that form a conglomeration [1,2]. They may be composed of hair (trichobezoars), vegetable matter (phytobezoars), milk curd (lactobezoars), and, very rarely, stones (lithobezoars) [3]. Lithobezoars are very rare in childhood and are most often seen in neglected and emotionally disturbed children [4,5]. This study aimed to present the clinical features of a 15-year-old male patient with a history of pica and iron deficiency that did not respond to oral iron therapy, and to highlight the diagnostic and management challenges of childhood lithobezoars.

A 15-year-old boy was referred to our department with iron deficiency anemia. He had a history of constipation, recurrent abdominal pain, and fatigue for 5 years. The boy was a neglected child of a family with low socioeconomic status. He was working as a carpenter in wood industry. He appeared pale and had sensitivity in both lower quadrants of the abdomen. Laboratory findings were as follows: hemoglobin: $7.5 \mathrm{~g} \mathrm{dL}^{-1}$; MCV: $54 \mathrm{fL}$; serum iron: $8 \mu \mathrm{g} \mathrm{dL}^{-1}$; iron binding capacity: $395 \mu \mathrm{g}$ $\mathrm{dL}^{-1}$. Peripheral blood examination showed hypochromic microcytic anemia, anisocytosis, and target cells. Plain abdominal X-ray showed numerous opacities scattered within the small intestine, ileocecal valve, and descending colon (Figure 1). Detailed anamnesis showed that he had been eating pieces of charcoal for 8 years. Because the patient did not satisfactorily respond to long-term oral iron supplementation, he was referred to admit to a hematologist by his family practitioner. When he submitted us in Training and Research Hospital, parental iron therapy was applied because of the persistent anemia. He was referred to the department of psychiatry because of behavioral problems.

Bezoars result from pica, an appetite for unpalatable or non-nutritive objects. The etiology of pica is unknown; it may be a consequence of parental neglect and deprivation early in life. It is more commonly observed in impoverished, emotionally disturbed children of low socioeconomic status that often have a problematic home environment. A his- 


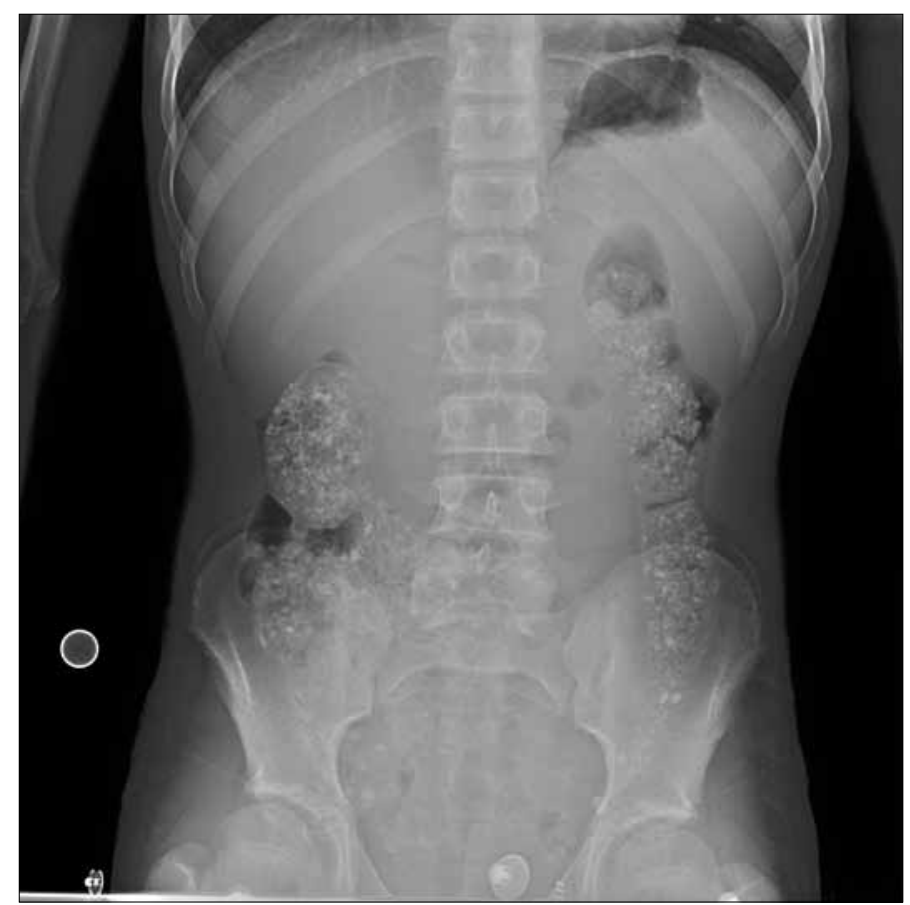

Figure 1. Plain abdominal radiograph shows opacities in the small intestine, ileocecal valve, and descending colon

tory of pica invariably precedes the formation of a lithobezoar [6]. The presented case also had pica.

Bezoar patients may present with a history of ingestion of sand, constipation, and recurrent episodes of abdominal pain that may result in significantly painful defecation, which is an important indication for the diagnosis of lithobezoars. Abdominal palpation and rectal examination provide important diagnostic evidence of colonic lithobezoars. Palpation of a prickly mass on rectal examination is known as the colonic crunch sign and can be observed in cases of sunflower seed bezoars and lithobezoars. Plain abdominal X-ray is especially important in the diagnosis of this type of colonic intraluminal mass. The presence of numer- ous radiopaque masses in the lower abdomen or the rectosigmoid junction, referred to as corn on the cob, is pathognomonic for lithobezoars [5,7].

In the presented case a history of ingestion of charcoal, iron deficiency anemia, constipation, and recurrent episodes of abdominal pain contributed significantly to the diagnosis. As in all cases of bezoars, psychiatric evaluation is essential to prevent recurrence. Early diagnosis and intervention are necessary in suspected cases of lithobezoars to avoid intestinal obstruction.

\section{Conflict of interest statement}

The authors of this paper have no conflicts of interest, including specific financial interests, relationships, and/or affiliations relevant to the subject matter or materials included.

\section{References}

1. Vijayambika K. Lithobezoar. Indian Pediatr 2004;41:1168.

2. Gürses, N, Ozkan K. Bezoars: analysis of seven cases. Z Kinderchir 1987;42:291-2.

3. Rao PL, Mitra SK, Pathak IC. Trichobezoars in children. Int Surg 1981;66:63-5.

4. Mohammad MA. Rectosigmoid lithobezoar in a eightyear-old. Afr J Paediatr Surg 2010;7:38-9.

5. Baran T, Ragip O, Abdulllah O, Naim K. Giant rectosigmoid lithobezoar in a child:four significant clues obtained from history, abdominal palpation, rectal examination and plain abdominal X-ray. Eur J Radiol 2004;49:23-4.

6. Narayanan SK, Akbar Sherif VS, Babu PR, Nandakumar TK. Intestinal obstruction secondary to a colonic lithobezoar. J Pediatr Surg 2008;43:9-10.

7. Numanoğlu KV, Tatli D. A rare cause of partial intestinal obstruction in a child: colonic lithobezoar. Emerg Med J 2008;25:312-3. 